\section{A Sequential Explanatory Mixed Method Study to Iden- tify Human Rights Violations and Asses the Psychosocial Health Status of the Internally Displaced Women of North- West Pakistan}

\author{
Hassan Mehmood Khan ${ }^{1 *}$, Kausar S Khan ${ }^{2}$ and Abdul Wahab \\ Yousafzai $^{3}$
}

${ }^{1}$ FATA Development Program (FDP), Deutsche Gesellschaft fuer Internationale Zusammenarbeit (GIZ) GmbH, Peshawar, Pakistan

${ }^{2}$ Department of Community Health Sciences, Aga Khan University, Karachi, Pakistan

${ }^{3}$ Department of Psychiatry, Shifa International Hospital, Islamabad, Pakistan

\begin{abstract}
\section{Background}

Millions of people are displaced each year due to conflicts worldwide, majority of them being displaced internally in their own countries. Although the number of Internally Displaced People (IDPs) is two times that of refugees, the IDPs don't get the aid meant for refugees as they don't cross international borders. Due to the ongoing war on terror, millions of people were displaced internally in North-West Pakistan including women and children, and there were press reports of human rights violations and psychosocial ill health among them. The objectives of our study were to estimate psychiatric morbidities among the internally displaced women of North-West Pakistan and to identify the human rights violations of these women. Methods
\end{abstract}

A sequential explanatory design of mixed method inquiry was used for this study. In the quantitative phase data was collected for psychiatric morbidities using a screening tool General Health Questionnaire (GHQ) 28 and for human rights violations and physical health related needs of the internally displaced women through a semi structured questionnaire from 308 displaced women. In the

*Corresponding author: Hassan Mehmood Khan, FATA Development Program (FDP), Deutsche Gesellschaft fuer Internationale Zusammenarbeit (GIZ) GmbH, Peshawar, Pakistan, Tel: +92 3459022992; E-mail: dr.hassanmehmoodkhan@gmail.com

Citation: Khan HM, Khan KS, Yousafzai AW (2017) A Sequential Explanatory Mixed Method Study to Identify Human Rights Violations and Asses the Psychosocial Health Status of the Internally Displaced Women of North-West Pakistan. J Community Med Public Health Care 4: 027

Received: February 04, 2017; Accepted: June 01, 2017; Published: June 14, 2017 qualitative phase data was collected for the human rights violations through in-depth interviews with 10 displaced women and 5 displaced men.

Results

According to our findings, $99.7 \%$ of the displaced women were scoring above the threshold for psychiatric morbidity and every one of them could be considered to be suffering from psychosocial ill health and their human rights and the rights as citizens of a country have been violated and the United Nations (UN) guiding principles on internal displacement were not being followed.

\section{Conclusion}

Of those studied, nearly all the internally displaced women of North-West Pakistan could be considered to be suffering from psychosocial ill health and evidence of human rights violations was discovered and there is a serious cause for concern regarding the violation of human rights of these IDPs. Their rights as citizens of a country have also been violated and the UN guiding principles on internal displacement are not being followed. The policy makers and humanitarian agencies should look into it by providing them all the basic necessities of life including food, water, privacy and protection of their honor, which were found to be lacking; and by initiating long term programs to take care of their mental health and rehabilitation as soon as possible.

\section{Background}

Conflict and displacement results in psychosocial stress and has a potentially negative impact on the mental health and well-being of affected people [1]. Findings indicate limitations in provision of psychosocial health services for displaced people, including management of severe mental disorders and lack of referral mechanisms to specialized mental health services [1]. Psychiatric morbidity is generally defined as a psychological or mental condition which leads to both psychological and physical deterioration [2]. The term usually applies to people who are very aware of their condition, despite the psychological and physical deterioration [2]. Psychological distress, posttraumatic stress disorder and major depressive episode have been recognized as the most common mental health issues amongst the uprooted populations $[3,4]$.

At the start of 2011, nearly 34 million people were displaced either internally or to other countries and regions around the world due to armed conflicts and political violence [5]. Internally Displaced People (IDPs) makes the largest group amongst the displaced and at the start of 2011 as many as 14.7 million people were internally displaced in 27 countries, though the total number of IDPs from conflict could be as high as 27.5 million [5]. By December 2015, there were more than 65 million displaced people due to conflicts across the globe and $50 \%$ of them were females [6].

There is an ongoing need to develop a culturally appropriate mental health services program for the displaced refugees [7]. A well planned social support enables resettled populations to meet their basic needs and improve their psychosocial health status [8]. Study findings recommend the need of continuous research on the psychosocial health and well-being of the resettled refugees and displaced people in 
order to develop effective resettlement strategies [9]. According to the United Nations High Commissioner for Refugees (UNHCR), forced displacement will continue to grow in the next decade [5].

The IDPs mostly have no other option than to seek assistance, protection, safety and security in the temporary camps in the destination areas. Whenever the humanitarian assistance in a camp is not organized and coordinated the vulnerability of the camp population increases. Gaps in humanitarian assistance in the camps lead to inequitable provision of services and inadequate protection [10]. Studies show that more than $90 \%$ of the IDPs don't feel safe in the temporary camps they have to live in [11].

\section{IDPs and human rights}

The IDPs mostly remain confined to the temporary camps created for them by governments and other agencies which mostly lack the basic fundamental rights such as freedom of movement and work [12]. The act of displacement not only violate the human rights of those displaced but also affect their ability to enjoy the basic needs and they are dependent on others for basic needs like water, food and shelter [13]. The IDPs should enjoy the same rights as do the other people in the same country. Like all the human beings the IDPs also have the right to dignity and mental, moral and physical integrity and the right to an adequate standard of living. All humanitarian assistance for the IDPs needs to be in accordance with the principles of humanity, equity and impartiality [14]. According to article 3 of the Universal Declaration of Human Rights, everyone has the right to life, liberty and security of person [15]. According to article 5 of the declaration no one shall be subjected to cruel, inhuman or degrading treatment [15]. Article 12 of the declaration says that no one shall be subjected to any kind of interference with his/her privacy, family or home and nor to attacks upon his/her honor [15]. Everyone has the right to the protection of the law against such interference or attacks. According to article 13 of the declaration everyone has the right to freedom of movement and residence within the borders of each state [15]. According to article 17 no one shall be deprived of his/her property [15]. Article 25 of the declaration says that everyone has the right to a standard of living adequate for the health and well-being of the person and her/his family and that women and children are entitled to special care and assistance [15]. Article 26 of the declaration says that everyone has the right to education [15].

\section{IDPs and psychiatric morbidities}

Conflict and displacement leads to stress and has the potential to negatively impact the mental health and well-being of the displaced people. These impacts have been studied and proven by many humanitarian workers, researchers and policy-makers around the world [1]. Findings highlight limitations in provision of mental health services for displaced people, including limited management of severe mental disorders and lack of proper referral mechanisms to specialized mental health services [1].

Some of the most common health or health related problems among the IDPs are psychiatric morbidities and human rights violations [16]. Post-Traumatic Stress Disorders (PTSD) and depression are common amongst the IDPs [17]. Major depressive disorders and suicidal tendencies are common in the internally displaced population [18]. A study in Uganda provides evidence on the impact of mental health of deprivation of basic goods, traumatic events, fear and uncertainty among displaced people [19]. In a study in Sri Lanka a clear dose-effect relationship between the exposure to conflict and war and PTSD severity was found among children [20]. In a study about the mental health of refugees following state-sponsored repatriation from Germany it was found that psychological stress among the refugees was of a considerable magnitude [21]. A cross sectional survey of the post conflict mental health status of the affected people in Sudan provides evidence of high levels of mental distress and associated risk-factors among the affected population, recommending a comprehensive psychosocial assistance in the affected region [22]. According to a systematic review the prevalence of posttraumatic stress disorder ranged from $11-23 \%$, anxiety from $25-77 \%$, and major depression from 11.5-57\% among Tibetan refugees [23]. According to another study in post war Serbia, 13.0\% participants had symptoms of PTSD, and $49.2 \%$ had symptoms of depression [24]. According to a survey in the Indian Kashmir valley, the ongoing conflict in the valley had a huge toll on the psychosocial health of the population with over one third of the participants having symptoms of psychological distress and majority of them being women [25]. According to an epidemiological study, $48 \%$ of the Somali and $32 \%$ of Rwandese refugees living in a refugee settlement were found to be suffering from PTSD [26]. In another study on the mental health status of the people displaced from Bosnia and Herzegovina due to conflict, mental health challenges were found to be present in more than $41 \%$ of those displaced [27]. Another study revealed that $62 \%$ of the Hurricane Katrina evacuees met the threshold criterion for Acute Stress Disorder (ASD) [28]. Refugees showed very high levels of psychosomatic and depressive symptoms as compared to civilians and soldiers in a longitudinal study in Croatia [29]. A study in the Tsunami affected regions found that the displaced survivors of Tsunami had significantly higher psychiatric morbidities as compared to the non-displaced people of the region [30]. A thesis that studied the mental health outcomes of the population that was displaced temporarily from Kosovo to Sweden showed that the prevalence of PTSD was $37 \%$ at baseline and increased significantly to $80 \%$ within 18 months of being displaced [31]. A brief review of research findings of the mental health consequences of war by Murthy and Lakshminarayana report that $42-72 \%$ respondents in Afghanistan, $17 \%$ in the Balkans, $15-55 \%$ in Cambodia, two thirds in Chechnya, $60-87 \%$ in Iraq, $9-76 \%$ in Israel, $16-42 \%$ in Lebanon, $11-54 \%$ in Palestine, about 25\% in Rwanda and 64\% in Sri Lanka had symptoms of psychiatric disorders [32].

\section{Internally displaced women}

Women are the most vulnerable group amongst the internally displaced people and the former UN Secretary General was quoted in 2002 as saying:

"The differential impact of armed conflict and specific vulnerabilities of women can be seen in all phases of displacement" [33].

Studies show that women and children are the most vulnerable population among the displaced people and psychosocial health needs are largely unmet in these populations [18]. Most of the Internally Displaced Women (IDW) report that they don't have autonomy to access health care and majority of them also report difficulties in breastfeeding due to the displacement [18]. There are restrictions on the freedom of movement and expression of the displaced women [18]. Women are also at risk of violence both within and outside the camps and displacement are reported to compromise resilience in women [34]. Studies on Internally Displaced Women (IDW) suggest that health services to them are severely lacking, the conditions in the camps established for them are unhygienic with lack of water [11]. The human rights of the internally displaced women cannot be 
realized without an appropriate understanding of the scenario they face and the question of IDPs cannot be solved without addressing the concerns and needs of the internally displaced women [11].

Research shows that conflict and displacement had a much greater effect on the health of the internally displaced women as compared to the health of the internally displaced men [19]. Studies provide evidence on the impact of displacement and deprivation of basic goods and services on both mental and physical health of the IDPs especially women [19].

\section{IDPs of North-West Pakistan}

Till July 2015, there were more than 1.8 million people displaced by insurgency, counterinsurgency and other related violence in NorthWest Pakistan [35]. Military operations against armed militants have forced hundreds of thousands of people to flee their homes since May 2014 [35]. By the end of 2014, up to 907,000 people were newly displaced, and as of July 2015, there were an estimated 1.56 million Internally Displaced People (IDPs) in North-West Pakistan [35]. Figure 1 shows the internal displacements in North-West Pakistan with hosting areas and areas of origin as of July 2015. International humanitarian organizations are supporting the in the response, but insecurity, bureaucracy and stringent government requirements have hindered access to those in need [35]. As of July 2015, around 4,300 families were living in the IDP camps in various locations in North-West of the country, where living conditions are poor with lack of privacy and security, and due to these reasons majority of IDPs are reluctant to stay in the camps [35]. The lives and physical security of the IDPs are threatened at all stages of their displacement [35]. In 2014, militants targeted government-run camps and a suicide bomber killed four people and injured eleven at one of the camps [35].

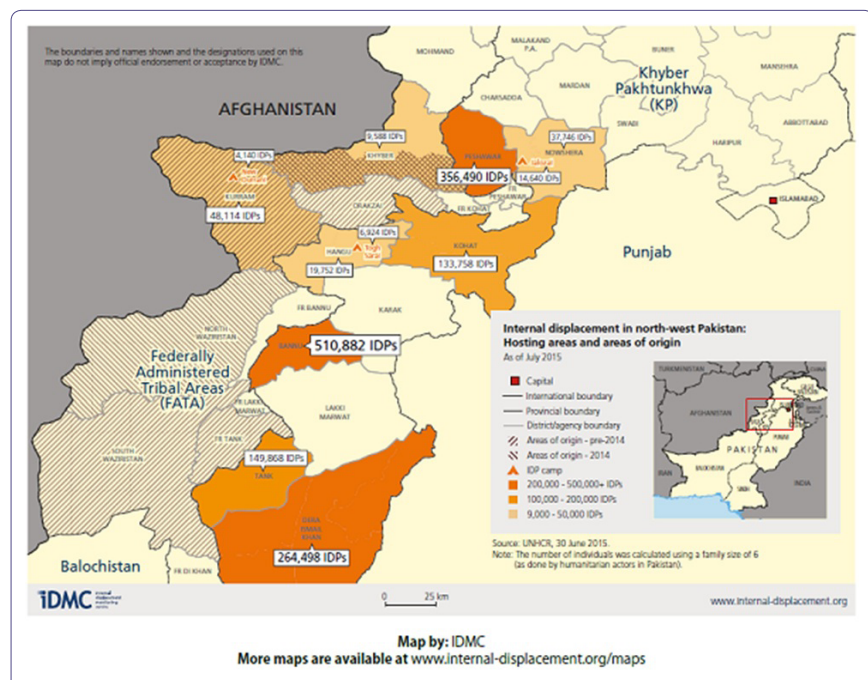

Figure 1: Internal displacement in North-West Pakistan: hosting areas and areas of origin-As of July 2015 [35].

\section{Internally displaced women of North-West Pakistan}

Women and children make up 77 per cent of the displaced population in North-West Pakistan [35]. Some of the most vulnerable IDPs, including women and children did not receive assistance [35]. A lack of female personnel and private space at registration points has also prevented women from registering and they also tend to avoid areas where assistance is provided for fear of harassment and gender-based violence [35]. Women's cultural need for privacy, has also limited their movement as IDPs and they feel unsafe while on the move, and when using toilet and washing facilities that in many cases are shared with men [35]. Internally displaced women's access to health services is inadequate, particularly for the pregnant and breastfeeding resulting in an increase in the number of miscarriages, premature births and infant deaths [35].

\section{UN Convention on the elimination of all forms of discrimi- nation against women}

Pakistan is a signatory to the UN Convention on the Elimination of all Forms of Discrimination against Women (CEDAW), which was adopted by the UN General Assembly on 18 December 1979 [36]. Pakistan ratified CEDAW on 12 April 1996 and a delayed compliance report was presented by Pakistan to the Committee on the elimination of discrimination against women in 2005 [37]. In 2007, the committee raised a list of issues and questions with regard to the consideration of an initial and periodic report by Pakistan [38]. The questions raised by the committee include the issues of women not having equal rights as men in many areas, female education, discrimination against women in employment, violence against women especially in tribal areas, honor killings, effectiveness of humanitarian assistance given to victims of disasters from a gender perspective and customs, practices and misinterpretation of religion as justifications for indulging in acts of discrimination against women [38]. Pakistan presented a report in reply to the questions raised by the committee, giving the details of the efforts being made by the governments in Pakistan for elimination of all kinds of discrimination against women and highlighting the steps been taken in this regard [39]. In the concluding comments of the Committee in response to Pakistan's reply to the issues and questions raised by the committee, the positive efforts and steps by the governments in Pakistan for elimination of all kinds of discrimination against women were praised while some more areas of concern were highlighted including the protection of the rights of migrant and displaced women and their families [40].

In this convention, discrimination against women was described as "any distinction, exclusion or restriction made on the basis of sex which has the effect or purpose of impairing or nullifying the recognition, enjoyment or exercise by women, irrespective of their marital status, on a basis of equality of men and women, of human rights and fundamental freedoms in the political, economic, social, cultural, civil or any other field" [36]. Under article 2 of the convention the state parties condemned all kind of discrimination against women and agreed to adopt a policy of eliminating discrimination against women by using all appropriate means including legislation without any delay [36]. Under article 5 the state parties agreed to eliminate all kind of prejudices and social and cultural customs and practices based on inferiority or superiority of either of the sexes [36]. According to articles 6 and 12 of the convention, the state parties agreed to take all kinds of steps to eliminate discrimination against women in access to education and health care respectively [36].

\section{The UN guiding principles on internal displacement}

According to the United Nations guiding principles on internal displacement, the IDPs shall enjoy in full equality, the same rights and freedom as do other citizens of that country and should not be deprived of the rights and freedom because they are internally displaced [41]. On $6^{\text {th }}$ March 2008, the UN General Assembly in its sixty second session, adopted a resolution for the protection of and assistance to 
internally displaced persons, because of the alarmingly high number of internally displaced people around the globe [42]. According to the United Nations guiding principles on internal displacement, the state authorities are responsible for providing proper accommodation to the IDPs and taking care of their security, nutrition, health and hygiene. It also says that informed consent should be taken from the people who are to be displaced and that displacement shall not be in a way that violates the rights to life, liberty, dignity and security [41]. The guiding principles on internal displacement also say that the IDPs should not be confined to a camp for longer durations. All the IDPs without any discrimination have the right to an adequate standard of living with adequate food, water, shelter, housing, clothing, health, sanitation and education. Principle 19 says that special attention should be paid to the needs of the Internally Displaced Women (IDW) including female health care providers and services. These principles were developed to serve as an international standard to guide governments and international humanitarian agencies in providing protection and assistance to the IDPs [41].

This study was conducted to explore the human rights status and the sufferings of the internally displaced women of North-West Pakistan during the conflict and in the whole process of displacement to see if these displaced women were getting the rights as declared in the universal declaration of human rights and if the UN guiding principles on internal displacement are being followed by the authorities or not; to explore if any kind of discrimination was being done against these women keeping in view the UN Convention on the Elimination of All Forms of Discrimination against Women (CEDAW); to identify the needs of these displaced women to inform the policy makers and humanitarian agencies and organizations to guide the future direction of humanitarian assistance for the internally displaced people and to explore the mental health status of these displaced women by assessing four subjective indicators of mental health i.e., somatic complaints, anxiety and insomnia, social dysfunction and depressive feelings.

\section{Methods}

\section{Study objectives}

1. To estimate the psychiatric morbidities among the internally displaced women of North-West Pakistan

2. To identify the human rights violations of the internally displaced women of North-West Pakistan

\section{Study setting}

The study was conducted at the temporary camps established for the Internally Displaced People (IDPs) of Federally Administered Tribal Areas (FATA) and Malakand Division, by the government in Peshawar, the provincial capital of Khyber Pakhtunkhwa (KP) province of Pakistan. The study was conducted in two of the camps in District Peshawar, namely the Kacha Ghari I and Kacha Ghari II camp respectively. These temporary camps were situated in the suburbs of Peshawar city. In these camps the internally displaced people live in tents provided by different agencies.

\section{Study design}

To achieve the objectives of the study there was a need to collect different types of data; data about the psychiatric morbidities among the internally displaced women and data about the human rights violations among these women. For this purpose a mixed method design was chosen as the most appropriate study design. Data about psychiatric morbidities among the internally displaced women was collected through a quantitative method through a structured tool for measuring psychiatric morbidities but for the data about the sufferings and human rights violations, an in-depth understanding was needed which was achieved through a qualitative method along with quantitative. A mixed method was chosen because it can answer a broader and more complete range of research questions and can produce complete knowledge needed to inform theory and practice [43]. Mixed methods studies are conducted to understand a research problem better by combining numeric trends of quantitative data and specific details of qualitative data to convey the needs of marginalized or vulnerable individuals and groups [44]. A sequential explanatory strategy of mixed method inquiry was used for this study $[45,46]$.

\section{General health questionnaire 28 (GHQ 28)}

For the psychiatric morbidities the General Health Questionnaire 28 (GHQ 28) was used [47] which has been widely used to screen psychiatric morbidities in community settings including those affected by war \& conflicts and in which four subjective indicators of mental health are assessed i.e., somatic complaints, anxiety and insomnia, social dysfunction and depressive feelings [48]. Examples of some of the items of GHQ 28 include 'Have you found everything getting on top of you?'; 'Have you been getting scared or panicky for no good reason?' and 'Have you been getting edgy and bad tempered?' Each item is accompanied by four possible responses, such as 'not at all', 'no more than usual,' 'rather more than usual' and 'much more than usual', scoring from 0 to 3 , respectively.

Using the alternative binary scoring method (with the two least symptomatic answers scoring 0 and the two most symptomatic answers scoring 1), the GHQ 28 classify any score exceeding the threshold value of 4 as achieving 'psychiatric caseness' [47], meaning that any person with the score of more than 4 on the GHQ 28 should be considered to be suffering from psychiatric morbidity. It should be noted here that the GHQ 28 is a screening tool and not a diagnostic tool and psychiatric caseness here is a probabilistic term and GHQ 28 is not usually used for predictive purposes however if such respondents presented in general practice, they would be likely to receive further attention [47].

The GHQ 28 has been developed by David Goldberg and has been validated in various languages and used on different populations [49]. Both English and Urdu versions of the GHQ 28 have been used and validated on Pakistani populations and both were found reliable for screening psychiatric morbidities in Pakistani populations [50]. The reliability coefficients of GHQ 28 have ranged from 0.78 to 0.95 in various studies [47]. The reliability coefficient of the Urdu version of the GHQ 28 has been reported as 0.90 [50]. The validated Urdu version of the tool was translated into Pashto by a bilingual expert and was back translated to Urdu by another bilingual expert. The needed amendments were made into the Pashto translation of the tool after this process of translation and back translation to make it as equal to the validated version as possible and was again translated and back translated by a bilingual expert before pretesting on a similar population and finalizing it for the formal data collection process. Data for the quantitative phase was collected by data collectors who were trained by the Principal Investigator before starting data collection.

\section{In-depth interviews}

To collect data about the sufferings and human rights violations during the process of internal displacement and in the temporary camps, in-depth interviews were conducted with the internally 
displaced women and men. Data collection for this phase was guided by the universal declaration of human rights, UN Convention on the Elimination of All Forms of Discrimination Against Women (CEDAW) and the UN Guiding Principles on internal displacement and an effort was made to find out if the internally displaced women of North-West Pakistan were getting their rights as per the universal declaration of human rights, to explore if any kind of discrimination was taking place against the displaced women and to see if the UN guiding principles on internal displacement are being followed by the authorities or not. For collecting qualitative data on sensitive issues and from a vulnerable population, the method of in-depth interviews from the participants has been recommended [51,52]. In the in-depth interviews both qualitative and quantitative methods were used to collect the needed information from the participants and data was collected for the human rights violations of the internally displaced women while in the conflict area and also during the whole process of internal displacement and also to assess the physical health related needs of these women. For the human rights violations data was collected from both men and women IDPs as women do not live in isolation of men and male perception of female vulnerability was an important aspect of this study. In this study both the quantitative and qualitative phases ran side by side and all the data was analyzed after data collection phase was completed. All interviews were conducted in pashto language for this phase. Data for the qualitative phase was collected by the Principal Investigator with the help of research assistants.

\section{Pretesting of instruments}

Data collection instruments were pretested in local language (Pashto) on a similar population ( $\mathrm{n}=30 ; 10 \%$ of sample size), before the actual data collection process for the study was started.

\section{Study population}

The study population was women and men 18 years or more, living in the temporary camps for the IDPs at Kacha Ghari in Peshawar.

\section{Inclusion criteria}

Women and men aged 18 or above, married or single, displaced either from Bajaur or Momand agencies of FATA and Malakand Division, living in the temporary camps for the IDPs at Kacha Ghari, Peshawar and giving informed consent was included in the study.

\section{Exclusion criteria}

The following women and men were excluded from the study:

1. The women and men living in the temporary camps for the IDPs but not displaced from Bajaur or Momand agencies of FATA and Malakand Division and present in the camp at the time of data collection as visitors or relatives of the IDPs living in Peshawar or elsewhere

2. The women and men not giving consent

3. The women and men who are not able to talk or express their selves due to any pathological or anatomical problem like speech disorders

\section{Sampling}

For the quantitative portion, systematic sampling technique was used [53]. Standing in the center of the camp facing east, a pen was swirled and thrown on the ground and in whichever direction the cap of the pen lied on ground, the first tent in that direction was selected to start data collection and after that every $6^{\text {th }}$ tent was selected and applying the inclusion and exclusion criteria one women was randomly selected from every $6^{\text {th }}$ tent for the survey, by using the pick from hat method. This process was continued till the estimated sample size was completed. For the qualitative portion a purposive sampling technique was used to conduct in-depth interviews with the study participants, both male and female [46,54]. For the qualitative phase participants were identified during the quantitative phase, which were willing to describe the situation in detail and provide as much information as needed to fulfill the objectives of the study. For this selection it was kept in mind to include participants of different age groups, different educational level, different marital status and all the three areas of origin i.e., Bajaur and Momand agencies of FATA and Malakand division.

\section{Sample size}

For the quantitative portion sample size was calculated for this study based on an estimated prevalence of conflict and displacement related health complaints of $83.4 \%$ in a previous study on the displaced population in Chechnya [48], with 5\% level of significance (confidence interval 95\%) with $10 \%$ bound on the error of estimation. Taking the number of IDPs of FATA and Malakand Division in the temporary camps as 93,323 , and among them 45,963 were females which equals $49.25 \%$ of the total IDPs in the camps. The number of adult IDPs aged 18 or above was estimated to be 34,166 , and to estimate the adult female IDP population $49.25 \%$ of 34,166 was calculated which came out to be 16,827 . The calculated sample size as per the below formula was 258 adult female IDPs.

$$
n=\frac{N \sigma^{2}}{(N-1) D+\sigma^{2}}
$$

Where

$$
\begin{aligned}
& \mathrm{N}=16827 \mathrm{~B}=0.1(10 \%) \\
& D=\frac{B^{2}}{Z_{\alpha / 2}^{2}} \\
& \sigma=(0.84-0.16)=0.68 \mathrm{Z}_{\alpha / 2}=1.96
\end{aligned}
$$

After adjusting for an assumed dropout rate (including refusal/ non-response) of $10 \%$ gave us the sample size of at least 284 adult female IDPs for the study to meet our objective. For the quantitative phase data was collected from 308 adult internally displaced women.

For the qualitative portion purposive sampling was done for the in-depth interviews with a purposive sample of participants and data was collected through in-depth interviews with 5 adult male and 10 adult female IDPs and the process was stopped once saturation was reached.

\section{Data analysis}

The quantitative data about the human rights violations was analyzed by using Microsoft Excel 2007. Frequencies were calculated for the demographic information and human rights violations. The quantitative data about the psychiatric morbidities, collected by using GHQ 28 was analyzed by using SPSS (Statistical Package for Social Sciences) version 15 using the alternative binary scoring method (with the two least symptomatic answers scoring 0 and the two most symptomatic answers scoring 1) and the standard cut-off score of 4 for the GHQ 28. Descriptive statistics were done and frequencies, means and standard 
deviations were calculated. Cross analysis of the data was also done by disaggregating the findings on the basis of age group, education level, area of origin, marital status and duration of displacement and means and standard deviations were calculated by using SPSS version 15 .

The qualitative data was analyzed manually and themes were generated from nodes and sub nodes as per the replies from the study participants.

\section{Integration}

In this study, we connected the quantitative and qualitative phases during the intermediate stage in the research process while selecting the participants for the qualitative phase from among the participants in the first, quantitative, phase. The second connecting point between the two phases in this study included developing the in-depth interview questions for the qualitative data collection based on the results of the first, quantitative, phase. We mixed the quantitative and qualitative approaches at the study design stage by introducing both quantitative and qualitative research questions and integrated the results from both the quantitative and qualitative phases during the interpretation of the outcomes of the entire study.

\section{Ethical considerations}

Approval was taken from the Ethical Review Committee (ERC) of The Aga Khan University Karachi for this study before starting the data collection process for the study. Informed consent was also taken from each participant in the local language before including her/him in the study.

\section{Results}

As the study has two phases i.e., a quantitative phase and a qualitative phase, the findings will be described in two sections separately for the quantitative and qualitative phases respectively.

\section{The quantitative phase}

The quantitative data was collected from 308 adult female IDPs and the quantitative tool had three portions for demographic information, human rights status and psychiatric morbidities respectively. In this section the findings of each of these portions will be described under three sub-headings.

\section{Demographic information}

All the 308 participants for the quantitative phase were adult female IDPs; they were grouped into seven categories of age groups as shown in table 1 . The maximum number of participants $(\mathrm{n}=92$, $29.8 \%$ ) were in the age group of 18 to 25 years of age, followed by 26 to 35 years $(n=72,23.3 \%)$ and 36 to 45 years $(n=71,23 \%)$. For the education level the participants were grouped into six categories as shown in table 1 , with majority of the participants $(\mathrm{n}=251,81.5 \%$ ) being illiterate and one of them a graduate. Most of the study participants $(\mathrm{n}=179,58.1 \%)$ were belonging to Bajaur agency and $(\mathrm{n}=96,31.1 \%)$ to Momand agency respectively as shown in table 1 . Majority of the participants $(\mathrm{n}=194,62.9 \%)$ were married followed by unmarried ( $\mathrm{n}$ $=67,21.7 \%)$ and widows $(\mathrm{n}=47,15.2 \%)$ respectively. Out of the total 241 married or widowed participants majority of them $(n=188,78 \%)$ had five or more children each, while 19 participants were pregnant at the time of data collection while more than half of them had at least one child under five years of age. Out of the 194 participants whose husbands were alive, the husbands of most of them were either daily wages workers $(n=71,29.5 \%)$, farmers $(n=51,21.2 \%)$ or jobless $(\mathrm{n}=28,11.6 \%)$ respectively. Majority of the participants $(\mathrm{n}=198$, $64.3 \%$ ) were displaced from their home towns for eight or more than eight months. The source of income of the household of the majority of the participants was either from daily wages $(n=121,39.3 \%)$, farming $(\mathrm{n}=70,22.7 \%)$ or were having no source of income $(\mathrm{n}=52$, $16.9 \%)$ and very few $(n=10,3.2 \%)$ had the Government's aid as a source of income. The minimum number of people in one household was 4 and the maximum number of people in one household was 28 while majority of the participants $(n=231,75 \%)$ were having 10 or more than 10 persons in their household. Most of the participants (n $=247,80.1 \%$ ) were having water supply from the main supply pipes of the camp while the source of food of the participants was either from their own source from the market $(\mathrm{n}=103,33.4 \%)$ or as aid from different sources $(n=142,46.1 \%)$.

\begin{tabular}{|c|c|c|}
\hline Category & No. of Participants (n) & Percentage (\%) \\
\hline \multicolumn{3}{|l|}{ Age group } \\
\hline $18-25$ years & 92 & 29.87012987 \\
\hline $26-35$ years & 72 & 23.37662338 \\
\hline $36-45$ years & 71 & 23.05194805 \\
\hline $46-55$ years & 30 & 9.74025974 \\
\hline $56-65$ years & 16 & 5.194805195 \\
\hline $66-75$ years & 15 & 4.87012987 \\
\hline$>75$ years & 12 & 3.896103896 \\
\hline Total & 308 & 100 \\
\hline \multicolumn{3}{|l|}{ Education level } \\
\hline Illiterate & 251 & 81.49350649 \\
\hline Primary or less & 41 & 13.31168831 \\
\hline Middle & 6 & 1.948051948 \\
\hline Matric & 8 & 2.597402597 \\
\hline Intermediate & 1 & 0.324675325 \\
\hline Graduate & 1 & 0.324675325 \\
\hline Total & 308 & 100 \\
\hline \multicolumn{3}{|l|}{ Area of origin } \\
\hline Bajaur agency & 179 & 58.11688312 \\
\hline Momand agency & 96 & 31.16883117 \\
\hline Malakand division & 33 & 10.71428571 \\
\hline Total & 308 & 100 \\
\hline \multicolumn{3}{|l|}{ Marital status } \\
\hline Married & 194 & 62.98701299 \\
\hline Unmarried & 67 & 21.75324675 \\
\hline Widow & 47 & 15.25974026 \\
\hline Total & 308 & 100 \\
\hline
\end{tabular}

Table 1: Demographic information of the study participants (Quantitative Phase).

\section{Human rights status}

According to majority of the participants $(n=273,88.6 \%)$ they didn't had enough food in the camp for their family and also not enough clothes $(n=256,83.1 \%)$ with them for themselves and their family in the camp. As for the freedom of movement, most of the participants $(n=209,67.9 \%)$ said that they were allowed to move around freely in the camp at their will while a still large number $(n=96$, $31.2 \%$ ) said they were not allowed to move freely in the camp at their will. When asked about the reason of their displacement from their 
homes, majority of the participants $(\mathrm{n}=246,79.8 \%)$ said that they were displaced due to Government's military operation, bombing or shelling. Majority of the participants $(n=196,63.6 \%)$ said they were allowed to move freely at their will in their home towns before displacement while a still large number $(n=101,32.8 \%)$ said they were not allowed to move freely at their will in their home towns before displacement. Majority of the participants $(n=225,73 \%)$ said that they were not able to carry out their daily life activities in the camp compared to a smaller number $(n=68,22 \%)$ who said they were not able to carry out their daily life activities in their home towns before displacement. An overwhelming majority of the participants ( $\mathrm{n}=$ $214,69.5 \%$ ) said that there were not enough washrooms/toilets in this camp for everyone to access. When asked about the education of their children almost half of the participants $(\mathrm{n}=144,46.8 \%)$ said that the children of their family don't go to school here in the camp, as compared to a smaller number $(n=98,31.8 \%)$ who said that the children of their family were not going to school before displacement in their hometowns.

More than half of the participants $(n=159,51.6 \%)$ said that their family member or members have been killed since the conflict started, either in their home town before displacement or in the process of displacement while more than half of them $(n=180,58.4 \%)$ also said that they have witnessed killings themselves during the conflict in their hometown before displacement. Almost $60 \%(n=179)$ of the participants said that they have witnessed torture/abuse during the conflict in their home town before displacement while almost $25 \%$ (n $=74$ ) of the participants said that they have witnessed torture/abuse in the process of displacement or in the camp. More than 30\% ( $\mathrm{n}=$ 93) of the participants responded that either healthcare services are not provided to them in the camp when they or anyone in their family gets ill or the treatment provided is not enough or not effective. Majority of the participants $(n=264,85.7 \%)$ were not satisfied with living in the camp. When the participants were asked about their greatest need in the camp, their response was electricity $(n=103,33.4 \%)$, followed by food $(n=53,17.2 \%)$ and money $(n=41,13.3 \%)$ respectively. More than $95 \%(n=294)$ of the respondents wanted to return to their homes as soon as possible but more than $92 \%(n=285)$ of them had no idea of their future or the possibility of their return to their homes.

\section{Psychiatric morbidities}

When GHQ 28 scores of all the 308 participants were analyzed for the subscale of somatic complaints using the alternative binary scoring method (with the two least symptomatic answers scoring 0 and the two most symptomatic answers scoring 1) and the standard cut-off score of 4 , it was found that $68.5 \%$ participants, for the subscale of anxiety and insomnia $59.4 \%$ participants, for the subscale of social dysfunction $76.6 \%$ participants and for the subscale of depressive feelings $54.2 \%$ participants were scoring above the cut-off score of 4 respectively and were achieving the score of psychiatric morbidity as shown in table 2. When GHQ 28 scores of all the participants were analyzed for the global total of all the 28 items, using the alternative binary scoring method and the standard cut-off score of 4 , it was found that $99.7 \%$ participants were scoring above the cut-off score of 4 and were achieving the score of psychiatric morbidity as shown in table 3. On further analysis the mean score of the 308 participants for the global total of all the 28 items was found to be 20.67 with standard deviation of 6.905 .

\begin{tabular}{|c|c|c|c|c|}
\hline \multicolumn{5}{|c|}{ Somatic Complaints } \\
\hline Score & Frequency & Percent & Valid Percent & Cumulative Percent \\
\hline 0 & 1 & 0.3 & 0.3 & 0.3 \\
\hline 1 & 5 & 1.6 & 1.6 & 1.9 \\
\hline 2 & 15 & 4.9 & 4.9 & 6.8 \\
\hline 3 & 33 & 10.7 & 10.7 & 17.5 \\
\hline 4 & 43 & 14 & 14 & 31.5 \\
\hline 5 & 8 & 2.6 & 2.6 & 34.1 \\
\hline 6 & 77 & 25 & 25 & 59.1 \\
\hline 7 & 126 & 40.9 & 40.9 & 100 \\
\hline Total & 308 & 100 & 100 & \\
\hline \multicolumn{5}{|c|}{ Anxiety \& insomnia } \\
\hline 0 & 2 & 0.6 & 0.6 & 0.6 \\
\hline 1 & 7 & 2.3 & 2.3 & 2.9 \\
\hline 2 & 38 & 12.3 & 12.3 & 15.3 \\
\hline 3 & 51 & 16.6 & 16.6 & 31.8 \\
\hline 4 & 27 & 8.8 & 8.8 & 40.6 \\
\hline 5 & 3 & 1 & 1 & 41.6 \\
\hline 6 & 23 & 7.5 & 7.5 & 49 \\
\hline 7 & 157 & 51 & 51 & 100 \\
\hline Total & 308 & 100 & 100 & \\
\hline \multicolumn{5}{|c|}{ Social dysfunction } \\
\hline 0 & 2 & 0.6 & 0.6 & 0.6 \\
\hline 1 & 20 & 6.5 & 6.5 & 7.1 \\
\hline 2 & 6 & 1.9 & 1.9 & 9.1 \\
\hline 3 & 28 & 9.1 & 9.1 & 18.2 \\
\hline 4 & 16 & 5.2 & 5.2 & 23.4 \\
\hline 5 & 34 & 11 & 11 & 34.4 \\
\hline 6 & 82 & 26.6 & 26.6 & 61 \\
\hline 7 & 120 & 39 & 39 & 100 \\
\hline Total & 308 & 100 & 100 & \\
\hline \multicolumn{5}{|c|}{ Depressive feelings } \\
\hline 0 & 11 & 3.6 & 3.6 & 3.6 \\
\hline 1 & 10 & 3.2 & 3.2 & 6.8 \\
\hline 2 & 72 & 23.4 & 23.4 & 30.2 \\
\hline 3 & 29 & 9.4 & 9.4 & 39.6 \\
\hline 4 & 19 & 6.2 & 6.2 & 45.8 \\
\hline 5 & 32 & 10.4 & 10.4 & 56.2 \\
\hline 6 & 24 & 7.8 & 7.8 & 64 \\
\hline 7 & 111 & 36 & 36 & 100 \\
\hline Total & 308 & 100 & 100 & \\
\hline
\end{tabular}

Table 2: Sub scores on GHQ 28 for the four subjective indicators of mental health.

Cross analysis of the data was done by disaggregating the findings on the basis of age group, education level, area of origin, marital status and duration of displacement and means and standard deviations were calculated. On the cross analysis of the global total scores of the participants on the GHQ 28 with their age groups it was found that the participants below the age of 35 years and above the age of 55 years were having mean scores of more than 20 with the participants above the age of 75 years having the highest mean score of 26.46 as shown in table 4 . On the cross analysis of the global total scores of the 


\begin{tabular}{|c|c|c|c|c|}
\hline Score & Frequency & Percent & Valid Percent & Cumulative Percent \\
\hline 0 & 1 & 0.3 & 0.3 & 0.3 \\
\hline 5 & 2 & 0.6 & 0.6 & 1 \\
\hline 6 & 2 & 0.6 & 0.6 & 1.6 \\
\hline 7 & 4 & 1.3 & 1.3 & 2.9 \\
\hline 8 & 16 & 5.2 & 5.2 & 8.1 \\
\hline 9 & 6 & 1.9 & 1.9 & 10.1 \\
\hline 10 & 3 & 1 & 1 & 11 \\
\hline 11 & 4 & 1.3 & 1.3 & 12.3 \\
\hline 12 & 8 & 2.6 & 2.6 & 14.9 \\
\hline 13 & 4 & 1.3 & 1.3 & 16.2 \\
\hline 14 & 2 & 0.6 & 0.6 & 16.9 \\
\hline 15 & 42 & 13.6 & 13.6 & 30.5 \\
\hline 16 & 17 & 5.5 & 5.5 & 36 \\
\hline 17 & 4 & 1.3 & 1.3 & 37.3 \\
\hline 18 & 2 & 0.6 & 0.6 & 38 \\
\hline 19 & 7 & 2.3 & 2.3 & 40.3 \\
\hline 20 & 8 & 2.6 & 2.6 & 42.9 \\
\hline 21 & 6 & 1.9 & 1.9 & 44.8 \\
\hline 22 & 6 & 1.9 & 1.9 & 46.8 \\
\hline 23 & 7 & 2.3 & 2.3 & 49 \\
\hline 24 & 8 & 2.6 & 2.6 & 51.6 \\
\hline 25 & 29 & 9.4 & 9.4 & 61 \\
\hline 26 & 38 & 12.3 & 12.3 & 73.4 \\
\hline 27 & 34 & 11 & 11 & 84.4 \\
\hline 28 & 48 & 15.6 & 15.6 & 100 \\
\hline Total & 308 & 100 & 100 & \\
\hline
\end{tabular}

participants on the GHQ 28 with their education level it was found that the participants who were graduates or having an intermediate level of education were having mean scores of 6 and 5 respectively while the participants having education level of matric or below were having mean scores of more than 20 as shown in table 4 . On the cross analysis of the global total scores of the participants on the GHQ 28 with their area of origin it was found that the participants belonging to Bajaur Agency were having mean score of more than 20 while the participants belonging to Momand Agency and Malakand division were having mean scores of less than 20 as shown in table 4 . On the cross analysis of the global total scores of the participants on the GHQ 28 with their marital status it was found that the participants who were married were having the highest mean score of 21.77 followed by the unmarried with 20.38 and the widows with 16.60 respectively as shown in table 4 . On the cross analysis of the global total scores of the participants on the GHQ 28 with their duration of displacement it was found that the participants having the duration of displacement between three to six months were having the highest mean score of 23.60 , followed by those with duration of displacement of more than six months having a mean score of 20.66 while those having a duration of displacement of less than three months were having the lowest mean score of 17.88 as shown in table 4 . So the cross analysis shows that the participants below 35 years of age and above 55 years of age with education level of matric or less than matric, belonging to Bajaur Agency, married and being displaced for more than three months were having high mean scores on the GHQ 28 and were more likely to be suffering from psychiatric morbidities like anxiety and depression.

\section{The qualitative phase}

In this section the qualitative findings will be described under different sub-headings to incorporate all the emerging themes from the analysis of the qualitative data.

\section{Water, food and clothes}

The quantity and quality of water that is available to a community is almost directly related to the health and well-being of that community as beside drinking water is needed to maintain hygiene and to perform the daily chores of life. From the quantitative data of this study it was found out that majority of the study participants get water from the main water supply pipes of the camp established by the camp authorities but through the qualitative data it was revealed that water wasn't available for them all the times especially at the times most needed and even if it was available it was too hot to use in the extreme hot weather conditions of the camp especially at day times as the camp was located in a region of extreme weather conditions and as the data was collected in the month of July, so most of the participants were complaining of unavailability of cold water and only those who could afford, would purchase some ice for themselves to have cold water to drink and the rest of them have to live with the hot water they were getting from the camp supply pipes.

Food is another basic necessity of life and most of the participants were purchasing food stuff from market on their own because the food provided to them at the camp by the camp authorities and as aid from different sources was either not enough for the large family size or was of a poor quality.

"Only 1 bag flour is given at the camp per month but that flour is also not good, at times we have found worms in it. And at one time I was shocked to see a dead frog in the flour bag they gave me here in this camp. Now when I get it I sell it in bazaar and get more clean flour for ourselves" (Male, 32 years, Bajaur).

As the participants had to run for their lives and leave their homes suddenly because they were not informed before the military operation was started in their areas, so most of them could not manage to bring any clothes and other stuff along them to the camp and everything was left behind and most of them reached the camp with just one or two pairs of clothes with them and they had to spend many days in the clothes they were wearing when they left home until they purchased some clothes for themselves or were given used clothes by some local people.

\section{Reason for displacement}

Most of the IDPs living in the Kacha Ghari camps were displaced about a year ago from their home towns in Bajaur and Momand agencies of FATA when Pakistani security forces started an operation against the militants in those areas when the militants started to increase their activities in those areas and tried to enforce their own writ in the region. The military operation in these areas was started suddenly without informing the people of that area beforehand so that they could have been safely moved to safer locations, due to the reasons best known to the security forces. According to the study participants they had no other choice but to run away with their women and children from their homes as bombs started to fall suddenly on their villages in the darkness of the night, so they either had to run 


\begin{tabular}{|c|c|c|c|c|c|c|c|}
\hline Age Group & Mean & $\mathbf{N}$ & Std. Deviation & Median & Minimum & Maximum & $\%$ of Total $\mathbf{N}$ \\
\hline $18-25$ Years & 21.43 & 91 & 6.922 & 25 & 0 & 28 & $29.50 \%$ \\
\hline $26-35$ Years & 21.35 & 74 & 6.033 & 24 & 6 & 28 & $24.00 \%$ \\
\hline 36 - 45 Years & 18.73 & 70 & 7.918 & 19.5 & 5 & 28 & $22.70 \%$ \\
\hline 46 - 55 Years & 17.53 & 30 & 5.841 & 15 & 8 & 28 & $9.70 \%$ \\
\hline 56 - 65 Years & 20.69 & 16 & 7.012 & 24.5 & 8 & 27 & $5.20 \%$ \\
\hline $66-75$ Years & 23.21 & 14 & 4.742 & 26 & 15 & 28 & $4.50 \%$ \\
\hline$>75$ Years & 26.46 & 13 & 3.55 & 28 & 15 & 28 & $4.20 \%$ \\
\hline Total & 20.67 & 308 & 6.905 & 24 & 0 & 28 & $100.00 \%$ \\
\hline \multicolumn{8}{|l|}{ Education level } \\
\hline Illiterate & 20.2 & 251 & 6.726 & 22 & 5 & 28 & $81.50 \%$ \\
\hline Primary or Less & 23.33 & 42 & 6.945 & 26 & 0 & 28 & $13.60 \%$ \\
\hline Middle & 23.2 & 5 & 6.907 & 26 & 11 & 28 & $1.60 \%$ \\
\hline Matric & 23.88 & 8 & 5.718 & 25.5 & 10 & 27 & $2.60 \%$ \\
\hline Intermediate & 5 & 1 &. & 5 & 5 & 5 & $0.30 \%$ \\
\hline Graduate & 6 & 1 & . & 6 & 6 & 6 & $0.30 \%$ \\
\hline Total & 20.67 & 308 & 6.905 & 24 & 0 & 28 & $100.00 \%$ \\
\hline \multicolumn{8}{|l|}{ Area of origin } \\
\hline Bajaur agency & 22.72 & 180 & 6.316 & 26 & 0 & 28 & $58.40 \%$ \\
\hline Momand agency & 17.23 & 96 & 6.228 & 15 & 5 & 28 & $31.20 \%$ \\
\hline Malakand division & 19.5 & 32 & 7.783 & 24.5 & 5 & 28 & $10.40 \%$ \\
\hline Total & 20.67 & 308 & 6.905 & 24 & 0 & 28 & $100.00 \%$ \\
\hline \multicolumn{8}{|l|}{ Marital status } \\
\hline Married & 21.77 & 193 & 6.186 & 25 & 5 & 28 & $62.70 \%$ \\
\hline Unmarried & 20.38 & 68 & 7.109 & 23 & 0 & 28 & $22.10 \%$ \\
\hline Widow & 16.6 & 47 & 7.923 & 15 & 5 & 28 & $15.30 \%$ \\
\hline Total & 20.67 & 308 & 6.905 & 24 & 0 & 28 & $100.00 \%$ \\
\hline \multicolumn{8}{|c|}{ Duration of displacement } \\
\hline 3 months or less & 17.88 & 41 & 8.019 & 17 & 0 & 28 & $13.30 \%$ \\
\hline $\begin{array}{l}\text { More than } 3 \text { months } \\
\text { up to } 6 \text { months }\end{array}$ & 23.6 & 40 & 5.042 & 25 & 8 & 28 & $13.00 \%$ \\
\hline More than 6 months & 20.66 & 227 & 6.787 & 23 & 5 & 28 & $73.70 \%$ \\
\hline Total & 20.67 & 308 & 6.905 & 24 & 0 & 28 & $100.00 \%$ \\
\hline
\end{tabular}

for their lives or die in their homes due to the shelling and bombing. The participants blamed both the Taliban and the Military for their displacement and misery.

"Both the Taliban and the military are killing innocent people and our children, so how can we stay there, I cannot watch my children being slaughtered by the Taliban or burnt alive by the military bombing" (Female, 58 years, Momand).

One of the themes emerging was that the military was bombing the villages and homes of innocent people of the area especially in Bajaur and Charmang areas and leaving the localities where the militants were operating untouched and unharmed. It was revealed that the Taliban were operating in the main Bajaur agency while the army was bombing and destroying villages in Charmang area in the suburbs of Bajaur.

\section{Freedom of movement}

According to the quantitative findings of this study, majority of the participants were allowed to move freely at their will in the camp and also in their home towns before displacement, but the qualitative findings reveled a different story. The main theme coming out in this category was that the women remain inside their tents all day and night in the hot conditions and they don't go outside as they have nowhere to go and at the most they go to the nearby tents to meet their neighboring women. The reasons for their restriction of movement in the camp were that it was an open camp with no security and privacy and the women have to follow the strict "Pardah" as per their cultural norms of their home towns (it means the women had to remain within a screen, curtain or veil in seclusion from the sight of men or strangers) and so they could not move out of the camp without any male member of the family. Another thing that was revealed was that some families including women and children were still trapped in their home towns due to one reason or another and their safety is being questioned by their relatives, neighbors and friends.

Regarding the freedom of movement in their home towns before displacement, the women were allowed to move freely at their will but only inside their homes especially when the activities of the militants started there and then the security forces entered the area, after that 
they were not able to go outside their homes or to the market either because of fear of the Taliban or due to curfews imposed by the military or restrictions on them by their men as they have to perform strict "pardah". Before the conflict they were able to move around in the area and go to the market but still in "pardah" (Vail). Once the conflict between the Taliban and the security forces was started then not only the females but the men were also not able to move freely mostly because of curfews to such an extent that they could not even go to the mosque to pray. Curfews were described as one of the major restriction on the freedom of movement in their home towns after the conflict started and the participants could not go out of their houses because of the fear of being killed as according to the participants any one seen outside in the curfew hours was shot dead on the spot without any investigation.

"Before coming here, we could move freely in our open and vast houses at our will, but not outside in the bazaar in those conditions when Taliban didn't allowed women to move around in the bazaars and were punished and also our men wouldn't allow us to go out because of that fear" (Female, 27 years, Momand)

\section{Displacement journey}

The displacement journey from their homes to the camp was described by the participants as not less than dooms day for them as they were suddenly woken up by bombings on their homes and they have to get up in shock and have to run away for safety along with their families. They have to walk on foot along with women and children for long distances for the whole night on the road and on mountains with no food or water on the way. They had to travel for distances more than 30 kilometers before they could get any transport and the transport was also not affordable for most of them and they had to walk till they reached safety on their way to the camps. The participants had to face many hardships on their way to the camps especially for those who were having children, old family members and patients with them and they had to take them along on the difficult terrains also before they could get any help from anyone. The participants had to cross many check posts both of the Taliban and the Military and have to face many body searches before coming out of the danger zone and then they were not properly guided by anyone about where to go to the camps and where to do registration and they had to face a lot of problems in registering themselves and getting accommodation in the camps and in the process the participants including women and children had to spend many days and nights on the roads in the open before getting any tent in the camp.

"It was a very hard journey for us. We were stopped at many places by "Taliban" and searched us and also in many places by military forces and they searched us also including our females. We had to walk for miles on foot in the mountains with no food or water and at times we got some transport for some distance. It took us more than 24 hours to reach here and normally it's a journey of only 3 hours. And then when we reached here we were sitting on the road for 17 days in the open air and for 17 days nobody gave us any tent or anything and me and my 4 sisters spent 17 days and nights here on the road" (Male, 18 years, Bajaur).

The participants were very upset with the sudden start of bombing on their villages by the military without informing them or taking them to safety due to which they had to suffer a lot in the displacement journey. Therefore the participants used very harsh words while describing their displacement. Apart from other hardships on the displacement journey there were also incidents of harassment of the lonely helpless females.

\section{Daily life activities}

According to the participants they were living a happy life back home and were doing everything as they wanted, could eat what they wanted and could carry out all the daily life activities like cooking, washing clothes, feeding children, taking baths, saying their prayers and all other chores in a good manner but after displacement in the camp they felt like they were in a jail and were being punished for some crime or sin. The women have to spend all the time inside the tent like a prison cell in extreme hot conditions and could not get out of the tent because there was no privacy and security in the camp. According to the participants there was a lot of disturbance in the camp, they could not sleep properly, the children keep crying all night and there is not enough space for the women to do all the activities like washing clothes and utensils, cooking, feeding children in one small tent with many people living in it.

"We don't want to be here like this, and what can we do here? Nothing, just spending time here because we have no other choice. We are not living here on our own happiness but we are forced to live here in these conditions. The females are held inside their tents 24 hours day and night, they can't do anything. I don't know for what sin we are being punished by Allah like this we were living in our house peacefully everyone was happy we never thought that this will happen to us. The females were in "pardah" there and their honor was not destroyed there and they were not humiliated like they are here" (Male, 32 years, Bajaur).

\section{Washrooms/toilets/privacy}

The emerging theme from the study was that there were washrooms and toilets build by the authorities in the camp but first of all they were built in the streets where the females could not go because of the "pardah" and their cultural norms of their area and secondly those washrooms and toilets were in bad condition, with no doors or broken doors and the sheets were torn by children and there was no maintenance of the washrooms and toilets by the camp administration and also the washrooms and toilets were not enough for the large population residing in the camp. Another fact was that there was no water at most of the times in those washrooms and toilets built by the camp administration. To solve this problem to some extent the camp inhabitants have made their own arrangements by digging holes near their tents or inside the tents in privacy for their use especially for the use of the female members of the family.

"We have made our own arrangements; we have dug holes to use as washrooms and toilets. The washroom and toilets made by the government in the camp are outside in the streets in the open, so how can our ladies go to these washrooms and toilets?, so we have made our own arrangements in "pardah" inside tents. We have strict "pardah" you know, our women can't go outside in the street to washrooms and toilets. I have so many times told myself along with my friends to the camp administrators to do something about these washrooms and toilets as they are in bad shape and unusable, but nobody listens to us. Especially the females have a lot of problem when they have to go to the washrooms and toilets as there are men moving around here all the time and there is no security, anyone can come into the camp at any time and move around wherever he wants to" (Male, 35 years, Bajaur). 


\section{Schooling of children}

According to the quantitative findings of the study the children of about $32 \%$ of the participant's families were not going to school in their home town before displacement and after displacement the number increased to about $47 \%$. From the qualitative data it was revealed that a school was established in the camp by the authorities for the children of the displaced people but it was closed down about 2 weeks back from the time of data collection due to reasons unknown to the participants and at the time of data collection the school in the camp was not functioning and the children of the displaced people were not going to school. Another theme that emerged was that the girls were not allowed to go to school and only the boys would go to school or a "madrassah" (Islamic religious school) both in the camp and in their home towns before displacement. According to the participants most of the schools especially the girl's schools have been destroyed either by the Taliban or by the bombing of the security forces.

"There was a small school made in a tent here initially and our children use to go there daily but now it has been closed since Friday, I don't know why. Now there is no school here in the camp" (Female, 46 years, Momand)

\section{Killings/torture/abuse}

Most of the participants of the study had at least one member of the family killed in the conflict in their home towns, either by the Taliban or by the bombing and shelling of the security forces.

"I have seen my husband die in front of my eyes when a rocket fell on our house" (Female, 70 years, Momand). It was also revealed that most of the participants had seen people being killed with their own eyes in the conflict. Another theme emerging was that both the Taliban and the military were involved in abuse and torture during the conflict in the home towns of the participants.

"I have seen the Taliban hanging a person in the "chowk" (Square), they are ruthless, you can't imagine that, they slaughtered many people like goats and sheep" (Male, 35 years, Bajaur).

"Well this is torture and abuse when you are dropping bombs on people's houses in the night and killing people including innocent children and women who have done nothing wrong" (Male, 60 years, Bajaur).

Although there was less talk of any physical abuse by anyone in the camp after displacement but the emerging theme was that their rights were not being given to them in the camp and it was described by the respondents as abuse.

\section{Healthcare services}

According to the participants, the healthcare services provided to the IDPs in the camp were neither enough nor effective and the participants revealed that only a few tablets were given to them when they go to the health center established for them in the camp by the authorities, which is being run by an NGO with the support of WHO. The participants revealed that the same kinds of tablets are provided to anyone who visits the health center and that they have to get treatment from outside the camp with their own resources especially the expensive medicines are purchased by the participants from the market.
"Here in this hospital in the camp they just give everyone some tablets and nothing else and mostly we have to get treatment from outside when someone gets ill, especially there is nothing here to deal with the emergency cases" (Female, 19 years, Malakand).

\section{Living conditions in camp/satisfaction in camp}

The participants were dissatisfied with the living conditions in the camp and were upset and angry over the treatment being met out to them in the camp after displacement from their home towns.

"We are being treated like animals here, no one cares for us, aren't we human beings, what wrong have we done to be humiliated in such a way? [With angry voice]" (Female, 50 years, Bajaur).

The theme that emerged from the qualitative data was that the participants were not treated as equal human beings as the other citizens of the country and this theme emerged from the responses of both the male and female participants as there was no difference in the responses of the male and female participants regarding the living conditions and satisfaction in the camp.

"We were respectable people in our area and were living with honor and dignity, but here we have been turned into beggars" (Male, 35 years, Bajaur).

The respondents were so angry and upset about the conditions they were living in that they used very harsh words while describing the situation.

"Not at all as I told you before we are not living here of our own choice but we don't have anywhere else to go. We are being treated like we are aliens or someone of a lower species than human beings. We are human beings as everyone else then why are we not treated like human beings, why have we been kept in these cages in this heat. At times it seems to me that we are some prisoners of war, being kept here by an enemy country and are being tortured" (Male, 32 years, Bajaur).

While comparing their lives in the camp after displacement with the lives of the other citizens of the country who were living in their homes, the participants said that there was a lot of difference in their lives as they were living a miserable life in the camp with no rights and no facilities being provided to them while the other citizens of the country were living a much better life happily in their homes without any tension or misery.

\section{Greatest need}

As the participants belonged to a much cooler region of the country and the camp at Kacha Ghari Peshawar was located in a region of extreme weather conditions and the data was collected for this study in the month of July, the hottest month of the year in that area therefore electricity and fans were considered to be the greatest needs by the participants.

"We can't live here in this heat anymore, our children are dying from the heat, there is no electricity, no fans, no cold water, no shade and this tent is like a "tanoor" (Oven)" (Female, 70 years, Momand).

There was also no trees or shades in the camp premises and all the tents were erected directly under the sun in the open so majority of the participants were very upset about the extreme hot conditions in the tents and this thing was reflected in their replies when they were asked about their greatest need in the camp.

"At the moment currently, electricity is the greatest need here. Fans are needed and also clean water must be provided here, it is very 
important. And above all we want our homes back. We want peace, respect and honor and we want to be treated like human beings and not like animals" (Male, 32 years, Bajaur).

Money and other items of daily use were also mentioned by the participants as their greatest needs in the camp and one of the theme emerged was that they need almost every item of daily life. Another theme that emerged from the data was that the participants said that they were being humiliated and that the honor of their females was not protected. When the male participants of the study were asked about the greatest need of the female members of their family, protection from the heat and sun was described as the major need of the female members of the families and also the lack of privacy "Pardah" was also considered to be a major problem for the females in the camp.

"The respect and honor that I had in my homeland has been snatched from me here. The honor of our mothers and sisters is not protected here in this camp; we have suffered a lot in these camps. Those who are dishonoring our mothers and sisters in every way they should face the reward from Allah as they are not the people to be forgiven we have been destroyed religiously, socially, culturally and mentally. I want to say that the only solution for all of our hardships and problems is in peace in our homeland and this country. When peace returns to our homeland than we don't care about these tents or these flour bags or anything else they want to give us, we don't need anything else then. If I go home I will sleep on the soil, will eat dry bread or even I will accept death from hunger in my home but can't live here like this. Give peace to our homeland we ask for nothing from you, give us nothing, just give peace to our homeland and let us go back to our homes (tears in eyes)" (Male, 35 years, Bajaur).

\section{Return plan}

The participants didn't want to stay in the camp anymore as they were fed up and upset over the living conditions in the camp and wanted peace to return to their home towns as soon as possible. Although majority of the participants were eager to return to their homes but most of them didn't knew anything yet about their return plan. Nobody has told them anything yet about when they will be sent back to their homes in peace and they were concerned about the delay in their repatriation to their homes as the IDPs of Swat and Dir were returning back to their homes much earlier than them. They had no idea about how much longer will they have to live in the camps.

"Nobody has told us anything. Still there is bombing going on our houses. Our houses have all been bulldozed. We have been provided cards and on them it is written that we have to spend 3 years in this camp. I am telling you if we stay in this camp for 3 years then "Inshallah" (God willing) no one of us will be alive by then. I swear if things get better today I won't spend another day, another night or even another second here anymore. I will leave immediately. I would like to die of hunger in my homeland no problem but I can't accept this life of humiliation that is been given to us here (deep sigh)" (Male, 35 years, Bajaur).

\section{Discussion}

The findings of this study show that the internally displaced women of North-West Pakistan and their families had not enough food and clothes, were receiving unhealthy food items, the water provided to them was too hot to use in the hot weather conditions of the camp, were not having proper washroom/toilet facilities and were not provided privacy and security in the camp. The findings also show that the healthcare services provided to the camp inhabitants were not satisfactory, there were restrictions on the movement of women, education of the children was suffering and the women were facing harassment and hardships during the process of displacement. The participants were not informed before being forced to flee their homes, their family members were being killed and tortured during the conflict and the prolonged displacement was compromising their physical and psychosocial health. There was uncertainty about their future and many of their friends and relatives were still trapped in their home towns in the conflict zone and on their way to the camps.

This is one of the first studies to quantify the factors that influence the overall physical and mental health of internally displaced persons in this region. Studies in the past have provided evidence that deprivation of basic goods and services, fear and uncertainty has a negative effect on the physical and mental health of the displaced people [19]. A study in Uganda also found that lack of safety in the camps had a strong negative association with mental health of the inhabitants of the camp [19]. In the south Asian region, systems of care and protection in temporary camps are mostly gender insensitive [55]. Our study has quantified all these factors among the internally displaced women of North-West Pakistan.

\section{Psychiatric morbidities}

To our knowledge this is the first study of the psychosocial health and human rights status of the Internally Displaced Women (IDW) of North-West Pakistan. The General Health Questionnaire (GHQ 28) showed high levels of medical and psychosocial needs. Living conditions in the camps at Peshawar were reported extremely harsh. Our findings on the General Health Questionnaire 28 (GHQ 28) [47] indicated that $99.7 \%$ of the IDW were suffering from mental health complaints such as somatic complaints, anxiety/insomnia, depressive feelings or social dysfunction when applying the recommended cutoff score for this questionnaire. This is substantially higher than findings from elsewhere: for example a study from Iran using the same instrument and cut off found a prevalence of only $17 \%$ [56] and in another study on the IDPs in Chechnya and Ingushetia the GHQ 28 with the cut off score of 5 used and the prevalence was found to be $98.8 \%$ [48]. Participants below 35 years of age and above 55 years of age with education level of matric or less than matric, belonging to Bajaur agency, married and being displaced for more than three months were more likely to be suffering from psychiatric morbidities like anxiety and depression. A study in Uganda found an association between mental health, age, gender and marital status of internally displaced people [19].

Prolonged exposure to traumatic events is associated with higher levels of mental health problems and poorer physical health [48], and witnessing extreme violence is also associated with psychosocial and mental health problems like depression, generalized anxiety disorder and post-traumatic stress disorder $[48,57,58]$. Nearly all of the people interviewed wished to return to their place of origin but could not do so as the situation was still not normal there. Attention must be paid to the psychosocial health of the study population since prolonged states of psychiatric morbidities can cause changes in patterns of living that are associated with physical and mental damage [48,59]. A study in South Darfur Sudan showed a considerable high prevalence of depression which was considered to be a challenge for the humanitarian agencies in Sudan [18]. Another study in Uganda provides evidence on the impact on health of deprivation of basic goods and services, traumatic events, and fear and uncertainty amongst displaced and crisis affected populations [19]. Among the consequences of war, the 
impact on the mental health of the civilian population is one of the most significant and studies of the general population in different regions of the World show a definite increase in the incidence and prevalence of mental disorders [33]. In one study of links between traumatic experiences during the 1994 Rwandan genocide, nearly a quarter of the respondents were found to have symptoms of Post-Traumatic Stress Disorders (PTSD) [60]. Another study of mental health and attitudes among Kosovar Albanians following the 1998-1999 war, revealed an association between traumatic events during the war, mental health disorders and impaired social functioning [60,61]. Even according to the DSM IV system (Diagnostic and Statistical Manual of Mental Disorders number IV) [62], anxiety and depression have been found to be more common in trauma-affected people than was originally assumed $[58,63,64]$, but although nearly all people affected by war and conflicts will suffer various negative responses such as nightmares and fears, they will not all develop psychiatric disorders [48] because there are individual ways of adapting to such stressful conditions that should not be overlooked [48]. Although conflict related mental health remains a comparatively neglected area of research, but current evidence suggests that mental disorders increase in conflict situations, and that human rights violations in such situations may also have negative impacts on mental health of the people living in the conflict zones $[60,65]$. Thus the findings of our study regarding the psychiatric morbidities are consistent with the findings of similar studies in different parts of the World. Like other indirect conflict related mortality and morbidity, negative mental health impacts are also part of the overall human cost of any conflict, and should be included in the broader impact assessments of conflicts [60].

\section{Human rights violations}

Studies around the world have found a correlation between human rights violations and adverse health outcomes $[60,66]$. By correlating health status to human rights violations during conflicts, researchers have provided evidence which can be useful to human rights monitors and humanitarian agencies and organizations [60]. According to the findings of our study the internally displaced women of North-West Pakistan are not given the same rights as other citizens of the country. No informed consent was taken from them before being forced to flee their homes. They are denied the right to liberty, security and education, and they are subjected to inhuman and degrading treatment and are denied privacy in the camp. They are not provided a standard of living adequate for health and well being and there is discrimination going on against women in access to education and health. In this section the findings of our study regarding the human rights violations among the internally displaced women of North-West Pakistan will be discussed in the light of the three documents which were used to formulate a list of possible human rights violations.

\section{The universal declaration of human rights}

The findings of our study show that the human rights situation in the IDP camps of North-West Pakistan is contrary to the universal declaration of human rights, adopted and proclaimed by UN general assembly resolution 217 A (III) of 10 December 1948 [15]. The findings are contrary to article 2 of the declaration according to which everyone was entitled to all the rights and freedoms without distinction of any kind [15]. The findings were also contrary to article 3 of the declaration which says that everyone has the right to life, liberty and security of person [15]. The findings also defy article 5 of the declaration according to which no one shall be subjected to torture or to cruel, inhuman or degrading treatment [15]. The findings of the study are also contrary to articles 12, 13, 25 and 26 of the declaration which are related to privacy, freedom of movement, standard of living and education respectively [15].

\section{The UN guiding principles on internal displacement}

The findings of this study also indicate that the UN guiding principles on internal displacement [41] are not being followed in NorthWest Pakistan. Principle 1 says that IDPs shall enjoy, in full equality, the same rights and freedoms under international and domestic law as do other persons in their country and that they shall not be discriminated against in the enjoyment of any rights and freedoms on the ground that they are internally displaced [41] but the findings of our study show that the IDPs of North-West Pakistan were not enjoying the same rights and freedoms as do other citizens of Pakistan. Principle 3 says that national authorities have the primary duty and responsibility to provide protection and humanitarian assistance to internally displaced persons within their jurisdiction [41] but this was not the case in Pakistan as shown by this study. According to Principle 7, informed consent of those to be displaced shall be sought [41] but the findings of this study shows that the IDPs of North-West Pakistan were not informed by anyone before the operation was started and they had to run for their lives. Principle 8 says that displacement shall not be carried out in a manner that violates the rights to life, dignity, liberty and security of those affected [41] but the situation was contrary to this in the IDP camps in Peshawar. According to Principle 18 all internally displaced persons have the right to an adequate standard of living [41] but the living conditions in the IDP camps in Peshawar were not up to adequate standard. Principle 18 also says that at the minimum, regardless of the circumstances, and without discrimination, competent authorities shall provide internally displaced persons with and ensure safe access to essential food and potable water, basic shelter and housing, appropriate clothing and essential medical services and sanitation and it further says that special efforts should be made to ensure the full participation of women in the planning and distribution of these basic supplies [41] but the findings of our study defy this.

\section{The UN convention on the elimination of all forms of dis- crimination against women}

Pakistan being a signatory to the UN Convention on the Elimination of All Forms of Discrimination Against Women (CEDAW) was bound to abide by all the articles of the convention. In this convention, discrimination against women was described as "any distinction, exclusion or restriction made on the basis of sex which has the effect or purpose of impairing or nullifying the recognition, enjoyment or exercise by women, irrespective of their marital status, on a basis of equality of men and women, of human rights and fundamental freedoms in the political, economic, social, cultural, civil or any other field" [36]. The findings of this study suggest that discrimination was going on against the internally displaced women of North-West Pakistan as they were not allowed to move freely at their will and the right of education was denied to them. Under article 2 of the convention the state parties condemned all kind of discrimination against women and agreed to adopt a policy of eliminating discrimination against women by using all appropriate means including legislation without any delay [36] but our findings suggest that discrimination was going on against the internally displaced women of North-West Pakistan. Under article 5 the state parties agreed to eliminate all kind of prejudices and social and cultural customs and practices based on inferiority or superiority of either of the sexes [36] but in the case of internally displaced women 
of North-West Pakistan, social and cultural customs and practices were denying the right of freedom of movement, the right to education and the right to an adequate standard of living to these women. According to articles 6 of the convention, the state parties agreed to take all kinds of steps to eliminate discrimination against women in access to education [1] but our study revealed that there was discrimination against the displaced women of North-West Pakistan in access to education.

\section{Study limitations}

The main limitation was that the Pashto version of GHQ 28 questionnaire was not a validated version but a translation from the validated Urdu version of the same instrument. The findings of this study cannot be generalized for all the internally displaced people of NorthWest Pakistan as the scope of the study was to estimate psychiatric morbidities and to identify human rights violations among those displaced people who were living in the IDP camps established for them by the government and therefore it did not include those IDPs who were living with friends and relatives or by their own outside the camps in Khyber Pakhtunkhwa or in the other three provinces of $\mathrm{Pa}$ kistan. We also recognize the fact that the GHQ 28 does not diagnose psychiatric morbidities as it is a screening tool and not a diagnostic tool. Psychiatric morbidity has to be confirmed by use of the Clinical Interview Schedule (CIS).

\section{Recommendations}

The following recommendations have been based on the findings of this study:

1. The camps for the IDPs should be established at locations with similar weather conditions to those of their places of origins and not in places with extreme weather conditions

2. The people that are being displaced should be informed before any action is started and they should be settled properly and safely to safer locations before starting any operations in their areas

3. While establishing a camp for the IDPs the cultural norms and values should be considered and taken care of like in the establishment of washrooms and toilets and privacy

4. The IDPs rehabilitation programs should include a mental health component

5. Measures should be taken so that the education of the displaced children does not suffer and education facilities should be made available for both girls and boys

6. Enough and healthy food and drinkable water supply must be made available in all the IDP camps

7. Efforts should be made to follow the UN's Guiding Principles on Internal Displacement and the Universal Declaration of Human Rights while dealing with the IDPs especially women

8. The government of Pakistan should take all those measures to which they have agreed to by becoming a signatory to the UN Convention on the Elimination of All Forms of Discrimination against Women (CEDAW)

\section{Conclusion}

The findings of our study show that the internally displaced women of North-West Pakistan and their families had not enough food and clothes, were receiving unhealthy food items, the water provided to them was too hot to use in the hot weather conditions of the camp, were not having proper washroom/toilet facilities and were not provided privacy and security in the camp. The findings also show that the healthcare services provided to the camp inhabitants were not satisfactory, there were restrictions on the movement of women, education of the children was suffering and the women were facing harassment and hardships during the process of displacement. The participants were not informed before being forced to flee their homes, their family members were being killed and tortured during the conflict and the prolonged displacement was compromising their physical and psychosocial health. There was uncertainty about their future and many of their friends and relatives were still trapped in their home towns in the conflict zone and on their way to the camps. Our findings indicated that $99.7 \%$ of the displaced women were suffering from mental health problems such as anxiety and depression. The internally displaced women of North-West Pakistan are not given the same rights as other citizens of the country. No informed consent was taken from them before being forced to flee their homes. They are denied the right to liberty, security and education, and they are subjected to inhuman and degrading treatment and are denied privacy in the camp. They are not provided a standard of living adequate for health and well being and there is discrimination going on against women in access to education, health and freedom of movement. The human rights situation in the IDP camps of North-West Pakistan is contrary to the Universal Declaration of Human Rights and the UN Guiding Principles on Internal Displacement are not being followed in North-West Pakistan. The policy makers, national \& international humanitarian agencies should look into the matter especially by establishing such camps at locations not having extreme weather conditions and by providing them all the basic necessities of life including food, water and privacy and protection of their honor, which were found to be lacking in the camp; and also long term programs are needed to take care of their mental health and rehabilitation as soon as possible because $99.7 \%$ of the participants could be considered to be suffering from psychiatric morbidities and wanted to return safely to their homes as soon as possible.

\section{List of Abbreviations}

IDP-Internally Displaced People

GHQ-General Health Questionnaire

UN-United Nations

UNHCR-United Nations Refugee Agency

WHO-World Health Organisation

IDW-Internally Displaced Women

FATA-Federally Administered Tribal Areas

CEDAW-Convention on the Elimination of All Forms of Discrimination Against Women

SPSS-Statistical Package for Social Sciences

ERC-Ethical Review Committee

PTSD-Post Traumatic Stress Disorder

ASD-Acute Stress Disorder

KP-Khyber Pakhtunkhwa

DSM IV-Diagnostic and Statistical Manual of Mental Disorders IV 


\section{Competing Interests}

The authors declare that they have no competing interests.

\section{Author's Contributions}

HMK led the study concept and design, data analysis, drafting of the manuscript, and participated in the data collection. KSK and AWY participated in developing the study concept and design, analysis and interpretation of data and review of the manuscript critically for important intellectual content. All authors read and approved the final manuscript.

\section{Author's Information}

HMK is currently working as a Technical Advisor Health at The FATA Development Programme, GIZ, Pakistan. KSK is an Associate Professor at the Department of Community Health Sciences, The Aga Khan University Karachi, Pakistan. AWY is a Consultant at the Department of Psychiatry, Shifa International Hospital Islamabad, Pakistan.

\section{Acknowledgement}

We thank all the respondents who participated in this study and gave their precious times to the study. We gratefully acknowledge the efforts of the members of the data collection teams as well as the administration of the IDP camps at Kacha Ghari Peshawar for their cooperation and are also thankful to the district administration of Peshawar for their permission to conduct the study in Peshawar.

\section{Disclaimer}

The views expressed in the article reflect the personal opinion of the authors, not of their organizations.

\section{References}

1. Meyer S (2013) UNHCR's mental health and psychosocial support for Persons of Concern. Global Review - 2013, United Nations High Commissioner for Refugees, Geneva, Switzerland.

2. Armiya'u AY, Obembe A, Audu MD, Afolaranmi TO (2013) Prevalence of psychiatric morbidity among inmates in Jos maximum security prison. Open Journal of Psychiatry 3: 12-17.

3. Guajardo MGU, Slewa-Younan S, Smith M, Eagar S, Stone G (2016) Psychological distress is influenced by length of stay in resettled Iraqi refugees in Australia. Int J Ment Health Syst 10.

4. Guajardo MGU, Slewa-Younan S, Santalucia Y, Jorm AF ( 2016) Important considerations when providing mental health first aid to Iraqi refugees in Australia: a Delphi study. Int J Ment Health Syst 10.

5. UNHCR (2012) The state of the World's Refugees - In Search of Solidarity. In: Kumin J (eds.). UNCHR, Geneva, Switzerland.

6. The Irish Consortium (2015) Women, War and Displacement: A review of the impact of conflict and displacement on gender-based violence: A report by The Irish Consortium on Gender-Based Violence. The Irish Consortium, Ireland, UK.

7. Murray KE, GR Davidson, Schweitzer RD (2010) Review of refugee mental health interventions following resettlement: best practices and recommendations. Am J Orthopsychiatry 80: 576-585.

8. Stewart MJ, Makwarimba E, Beiser M, Neufeld A, Simich L, et al. (2010) Social support and health: immigrants' and refugees' perspectives. Diversity $\&$ Health and Care.

9. Alemi Q, James S, Cruz R, Zepeda V, Racadio M (2014) Psychological distress in afghan refugees: a mixed-method systematic review. J Immigr Minor Health 16: 1247-1261.
10. The Camp Management Toolkit (2008) Norwegian Refugee Council. The Camp Management Toolkit, Oslo, Norway.

11. Ramazanov R, RA, Allahverdiyev I, Abdullahyeva L (2006) The Status of IDP Women in Azerbaijan - A Rapid Assessment. United Nations Development Fund for Women, Baku, Azerbaijan.

12. UNHCR ( 2006) The State of the World's Refugees. Oxford University Press, New York, USA.

13. Brookings Institution (2008) Protecting Internally Displaced Persons: A Manual for Law and Policymakers. Brookings Institution, Washington, D.C., USA.

14. Brookings (2005) Addressing Internal Displacement: A Framework for National Responsibility, Brookings, Washington, D.C., USA.

15. United Nations (1948) Universal Declaration of Human Rights. United Nations, New York, USA.

16. Thomas SL, Thomas SD (2004) Displacement and Health. Br Med Bull 69: 115-127.

17. Roberts B, Ocaka KF, Browne J, Oyok T, Sondorp E (2008) Factors associated with post-traumatic stress disorder and depression amongst internally displaced persons in northern Uganda. BMC Psychiatry 8: 38.

18. Glen Kim, Torbay R, Lawry L (2007) Basic health, women's health, and mental health among internally displaced persons in Nyala Province, South Darfur, Sudan. Am J Public Health 97: 353-361.

19. Roberts B, Ocaka KF, Browne J, Oyok T, Sondrop E (2009) Factors associated with the health status of internally displaced persons in northern Uganda. J Epidemiol Community Health 63: 227-232.

20. Catani C, Jacob N, Schauer E, Kohila M, Neuner F (2008) Family violence, war, and natural disasters: a study of the effect of extreme stress on children's mental health in Sri Lanka. BMC Psychiatry 8: 33.

21. Lersner UV, Elbert T, Neuner F (2008) Mental health of refugees following state-sponsored repatriation from Germany. BMC Psychiatry 8.

22. Roberts B, Damundu EY, Lomoro O, Sondorp E (2009) Post-conflict mental health needs: a cross-sectional survey of trauma, depression and associated factors in Juba, Southern Sudan. BMC Psychiatry 9.

23. Mills EJ, Singh S, Holtz TH, Chase RM, Dolma S (2005) Prevalence of mental disorders and torture among Tibetan refugees: A systematic review. BMC International Health and Human Rights 5.

24. Nelson BD, Fernandez WG, Galea S, Sisco S, Dierberg K, et al. (2004) War-related psychological sequelae among emergency department patients in the former Republic of Yugoslavia. BMC Medicine 2.

25. de Jong K, de Kam SV, Ford N, Lokuge K, Fromm S, et al. (2008) Conflict in the Indian Kashmir Valley II: psychosocial impact. Confl Health 2.

26. Onyut LP, Neuner F, Ertl V, Schauer E, Odenwald M, et al. (2009) Trauma, poverty and mental health among Somali and Rwandese refugees living in an African refugee settlement - an epidemiological study. Confl Health 3.

27. Carballo M, Smajkic A, Zeric D, Dzidowska M, Gebre-Medhin J, et al. (2004) Mental health and coping in a war situation: the case of Bosnia and Herzegovina. J Biosoc Sci 36: 463-477.

28. Mills MA, Edmondson D, Park CL (2007) Trauma and Stress Response Among Hurricane Katrina Evacuees. Am J Public Health 97: 116-123.

29. ProrokovicA, Cavka M, Adoric VC (2005) Psychosomatic and depressive symptoms in civilians, refugees, and soldiers: 1993-2004 longitudinal study in Croatia. Croat Med J 46: 275-281.

30. Math SB, John JP, Girimaji SC, Benegal V, Sunny B, et al. (2008) Comparative study of psychiatric morbidity among the displaced and non-displaced populations in the Andaman and Nicobar Islands following the tsunami. Prehosp Disaster Med 23: 29-34.

31. Roth G (2006) A prospective study of mental health among mass-evacuated Kosovo Albanians. Karolinska University Press, Stockholm, Sweden. 
Citation: Khan HM, Khan KS, Yousafzai AW (2017) A Sequential Explanatory Mixed Method Study to Identify Human Rights Violations and Asses the Psychosocial Health Status of the Internally Displaced Women of North-West Pakistan. J Community Med Public Health Care 4: 027.

32. Murthy SR, Lakshminarayana R (2006) Mental health consequences of war: a brief review of research findings. World Psychiatry 5: 25-30.

33. Buscher D (2006) Displaced women and girls at risk: Risk factors, protection, solutions and resource tools. Women's Commission for Refugee Women \& Children, New York, USA.

34. Almedom A, Tesfamichael B, Mohammed Z, Mascie-Taylor N, Muller J, et al (2005) Prolonged displacement may compromise resilience in Eritrean mothers. Afr Health Sci 5: 310-314.

35. Glatz AK (2015) Pakistan: solutions to displacement elusive for both new and protracted IDPs. Internal Displacement Monitoring Centre, Geneva, Switzerland.

36. UN Women (1979) The Convention on the Elimination of All Forms of Discrimination against Women. UN Women, New York, USA.

37. UN Women (2005) Consideration of reports submitted by States parties under article 18 of the Convention on the Elimination of All Forms of Discrimination against Women. Combined initial, second and third periodic reports. UN Women, New York, USA.

38. UN (2007) List of issues and questions with regard to the consideration of an initial and periodic report: Pakistan. United Nations Committee on the Elimination of Discrimination against Women, New York, USA

39. UN (2007) Responses to the list of issues and questions for consideration of the combined initial, second and third periodic report of Pakistan: Pakistan. The United Nations Committee on the Elimination of Discrimination against Women, New York, USA

40. UN (2007) Concluding comments of the Committee on the Elimination of Discrimination against Women, New York, USA.

41. UNOCHA (2004) Guiding Principles on Internal Displacement. UNOCHA, Geneva, Switzerland.

42. UN (2008) Resolution adopted by the General Assembly: 62/153. Protection of and assistance to internally displaced persons, UN, New York, USA.

43. Johnson RB, Onwuegbuzie AJ (2004) Mixed Methods Research: A Research Paradigm Whose Time Has Come. Educational Researcher 33: 14-26.

44. Hanson WE, Creswell JW, Clark VLP, Petska KS, Creswell JD (2005) Mixed Methods Research Designs in Counseling Psychology. Journal of Counseling Psychology 52: 224-235.

45. Creswell JW, Clark VLP, Gutmann ML, Hanson WE (2003) Handbook of Mixed Methods in Social \& Behavioral Research. Teddlie C, Tashakkori A (eds.). Sage Publications, California, USA.

46. Ivankova NV, Creswell JW, Stick SI (2006) Using Mixed-Methods Sequentia Explanatory Design: From Theory to Practice. Field Methods 18: 3-20.

47. Jackson C (2007) The General Health Questionnaire. Occupational Medicine 57: 79 .

48. de Jong K, van der Kam S, Ford N, Hargreaves S, van Oosten R, et al. (2007) The trauma of ongoing conflict and displacement in Chechnya: quantitative assessment of living conditions, and psychosocial and general health status among war displaced in Chechnya and Ingushetia. Confl Health 1: 4.

49. Nagyova I, Krol B, Szilasiova A, Stewart R, van Dijk JP, van den Heuvel WJA, et al. (2000) General Health Questionnaire-28: Psychometric Evaluation of the Slovak Version. Studia Psychologica 42: 351-361.
50. Riaz H, Reza H (1998) The evaluation of an Urdu version of the GHQ-28 Acta Psychiatrica Scandinavica 97: 427-432.

51. Mack N, Woodsong C, MacQueen KM, Guest G, Namey Emily (2005) Qualitative Research Methods: A Data Collector's Field Guide. Family Health International, North Carolina, USA

52. Ulin PR (2002) Qualitative Methods: A Field Guide for Applied Research in Sexual and Reproductive Health. Family Health International, North Carolina, USA.

53. Collins KMT, Onwuegbuzie AJ, Jiao QG (2007) A Mixed Methods Investigation of Mixed Methods Sampling Designs in Social and Health Science Research. Journal of Mixed Methods Research 1: 267-294.

54. Teddlie C, Yu F (2007) Mixed Methods Sampling: A Typology with Examples. Journal of Mixed Methods Research1: 77-100.

55. Manchanda R (2004) Gender Conflict and Displacement: Contesting 'Infantilisation' of Forced Migrant Women. Economic and Political Weekly 39: 41794186.

56. Noorbala AA, Bagheri Yazdi SA, Yasamy MT, Mohammad K (2004) Mental health survey of the adult population in Iran. Br J Psychiatry 184: 70-73.

57. Solomon Z (1988) Somatic complaints, stress reaction, and posttraumatic stress disorder: a three-year follow-up study. Behav Med 14: 179-185.

58. Warshaw MG, Fierman E, Pratt L, Hunt M, Yonkers KA, et al. (1993) Quality of life and dissociation in anxiety disorder patients with histories of trauma or PTSD. Am J Psychiatry 150: 1512-1516.

59. Lie B, Lavik NJ, Laake P (2001) Traumatic events and psychological symptoms in a non-clinical refugee population in Norway. Journal of Refugee Studies 14: 276-294.

60. Thoms ONT, Ron J (2007) Public health, conflict and human rights: toward a collaborative research agenda. Confl Health 1: 11.

61. Cardozo BL, Vergara A, Agani F, Gotway CA (2000) Mental health, social functioning, and attitudes of Kosovar Albanians following the war in Kosovo. JAMA 284: 569-577.

62. KR (1997) Psychobiology and clinical management of posttraumatic stress disorder. In: Boer D, Dekker M (eds.). Clinical management of anxiety: Theory and practical applications. Marcel Dekker, New York, USA.

63. Kessler RC, Sonnega A, Bromet E, Hughes M, Nelson CB (1995) Posttraumatic stress disorder in the National Comorbidity Survey. Arch Gen Psychiatry $52: 1048-1060$

64. Perkonigg A, Kessler RC, Storz S, Wittchen H-U (2000) Traumatic events and post-traumatic stress disorder in the community: prevalence, risk factors and comorbidity. Acta Psychiatr Scand 101: 46-59.

65. Checchi F, Gayer M , Grais RF, Mills EJ (2007) Public health in crisis-affected populations: A practical guide for decision-makers. Overseas Development Institute, London, UK.

66. Mullany LC, Richards AK, Lee Cl, Suwanvanichkij V, Maung C, et al. (2007) Population-based survey methods to quantify associations between human rights violations and health outcomes among internally displaced persons in eastern Burma. J Epidemiol Community Health 61: 908-914. 